\title{
Giant fibroepithelial polyp of the glans penis not associated with condom-catheter use: A case report and literature review
}

\author{
Hanmu Yan, MD; ${ }^{*}$ Ann Treacy, MRCPI, FRCPath; ${ }^{\dagger}$ George Yousef, MD, PhD, FRCPC; ${ }^{\dagger}$ Robert Stewart, MD, FRCSC ${ }^{\S}$
}

*Division of Urology, University of Toronto, Toronto, ON; ‘Department of Laboratory Medicine, St. Michael's Hospital, Toronto, ON; \&Division of Urology, St. Michael's Hospital, Toronto, ON

Cite as: Can Urol Assoc J 2013;7(9-10):e621-4. http://dx.doi.org/10.5489/cuaj.506 Published online September 10, 2013.

\section{Abstract}

Fibroepithelial polyps are rare benign tumours of the glans penis; there are only a few reported cases. The pathogenesis is unknown. However, they have been linked with chronic condom catheter use or prior penile surgery. We report a case of a 62-year-old man with a large fibroepithelial polyp of the glans penis of 11 years duration, which was not associated with condom catheter use or prior surgery. The mass was large, measuring $7 \times 5 \times 3 \mathrm{~cm}$. Fibroepithelial polyps have been reported in a range of genitourinary sites in males and females, adults and children, and in rare cases may be associated with malignant transformation. They should be considered in the differential diagnosis of both cutaneous and mucosal genitourinary lesions.

\section{Introduction}

Fibroepithelial polyps are rare benign tumors of the glans penis; there are only a few reported cases. The pathogenesis is unknown, however, they have been linked with chronic condom catheter use ${ }^{1}$ or prior penile surgery. ${ }^{2}$ It is speculated that chronic venous congestion occurs secondary to extrinsic compression caused by the condom catheter, and leads to stromal proliferation. ${ }^{1}$ Other theories implicate tumour formation secondary to chronic inflammation of the glans penis, ${ }^{3}$ or exaggerated regeneration during postoperative healing. ${ }^{2}$ We report a case of a 62 -year-old man with a large fibroepithelial polyp of the glans penis, which was not associated with condom catheter use or prior surgery.

\section{Case report}

A 62-year-old male presented with a large verrucous "grapelike" lesion on the glans penis lasting 11 years. It had origi- nally developed over the course of 3 months and had not changed in appearance over the course of follow-up. There was no travel history that could have predisposed him to filarial lymphedema. He had no urinary discharge and no voiding symptoms. Prior to developing the lesion, he was sexually active. He acquired a sexually transmitted infection at age 20, which resolved. He denied ever using a condom catheter. He denied ever having a constrictive device at the base of the penis, such a penile ring or vacuum device. There was no history of trauma. He had no comorbidities and was not taking medication.

On examination, a mass measuring $7 \times 5 \times 3 \mathrm{~cm}$ was present on the glans penis, extending to involve the frenulum, but sparing the urethra. There was significant redundancy and thickening of the penile shaft skin, with the brawny appearance of stasis dermatitis. The flaccid phallus was about $12-\mathrm{cm}$ long. There were also several small subcentimeter verrucous lesions around the penile skin near the corona. The scrotal contents were normal (Fig. 1a, Fig. 1b).

The patient underwent excision of the glans lesion and circumcision to remove redundant shaft skin and the several smaller lesions on the penile skin near the corona. Postoperatively, he voided without difficulty and had satisfactory cosmesis.

\section{Pathologic findings}

Examination of the penile mass excision revealed a polypoid lesion with epidermal hyperkeratosis, focal parakeratosis and hyperkeratosis. Hemosiderin-laden macrophages, stellate and multi-nucleated stromal cells and extensive edema were observed in the dermis. Areas of fibrosis were also identified. There was no evidence of dysplasia or malignancy (Fig. 2, Fig. 3). DNA was extracted from the paraffin embedded tissue and subjected to testing for 37 human papillomavirus (HPV) DNA genotypes. No evidence of HPV was detected by linear array analysis using genotype specific 


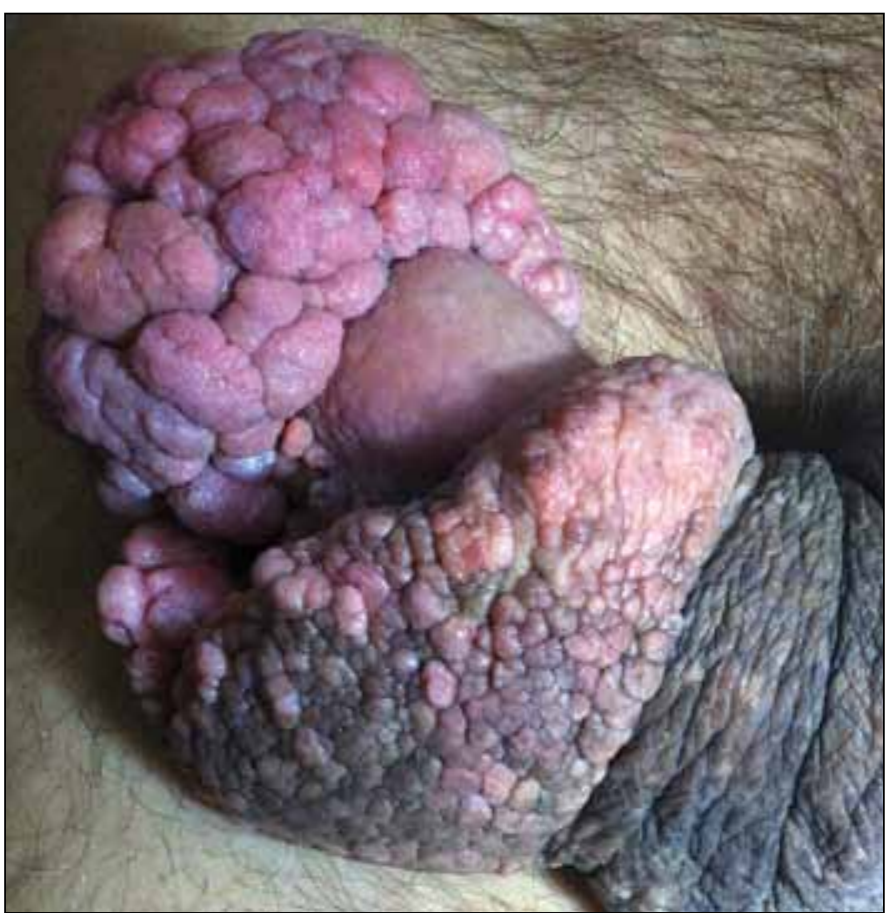

Fig. 1a. Macroscopic photograph of penile fibroepithelial polyp.

oligonucleotide probes. The histological features along with the negative HPV analysis were most in keeping with a giant fibroepithelial polyp of the penis.

\section{Discussion}

Fibroepithelial polyps (FEPs) are benign mesodermal tumours, which are composed of a core of fibro-vascular stroma with overlying epithelium. They are often referred to as skin tags or acrochordons and are found in multiple cutaneous locations measuring usually less than $10 \mathrm{~mm}$. Common sites for FEP include the groin, axilla and eyelids. There are also multiple reports of unusual presentations and sites of origin in the respiratory tract ${ }^{4}$ and orophyarynx. ${ }^{5}$ They are associated with diabetes and hyperlipidemia ${ }^{6}$ and not associated with colonic polyps as previously thought. ${ }^{7}$ Although the penis is not a common site of presentation, FEPs have been documented elsewhere in the genitourinary tract. ${ }^{8}$ In contrast to the squamous lining seen in cutaneous cases, FEPs of the genitourinary tract have a urothelial lining. ${ }^{8,9}$ In children they have been documented antenatally, ${ }^{10}$ and in many cases are thought to be congenital; ${ }^{11}$ however, they may occur in multiple sites in the lower urinary tract in children post-pyeloplasty. ${ }^{12,13}$

These polypoid or cauliflower-like masses have a median size of $2.5 \mathrm{~cm}$ (maximal size reported is $8 \mathrm{~cm}^{14}$ ), and usually involve the ventral glans penis. ${ }^{1,15,16}$ Clinically, the differential diagnosis includes condyloma acuminatum, giant condylomas (called Buschke-Löwenstein tumors), verrucous

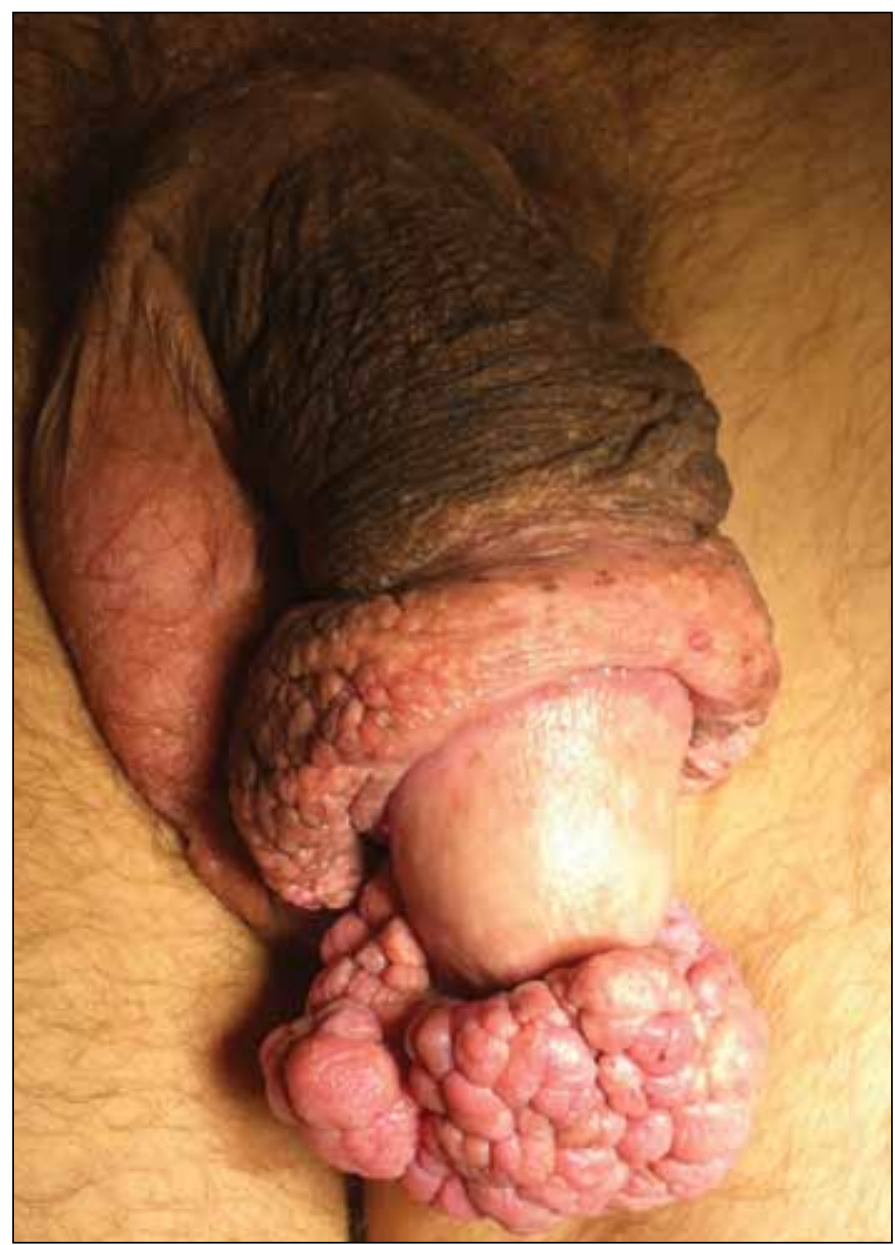

Fig. 1b. Macroscopic photograph of penile fibroepithelial polyp.

carcinoma, squamous cell carcinoma, urethral carcinoma and angiomyxoma. ${ }^{1}$

The pathologic diagnosis is aimed primarily at ruling out malignancy, a condyloma or a giant condyloma (BuschkeLöwenstein tumor). If urethral carcinoma is suspected, urethroscopy may be indicated. Giant condylomas are HPV-driven lesions and are known to undergo malignant transformation to squamous cell carcinoma. ${ }^{17} \mathrm{~A}$ tissue biopsy would identify typical features of squamous cell carcinoma.

A single report detailing development of squamous cell carcinoma of a penile FEP has been published, ${ }^{9}$ consistent with reports of malignant transformation in cutaneous FEPs. ${ }^{18}$ Similarly, a case of urothelial carcinoma has been reported in a ureteral FEP. ${ }^{19}$ Although our case showed no evidence of dysplasia or malignancy, we would advise careful sampling and examination of these lesions to exclude a primary malignancy or malignancy arising in the setting of a FEP.

Treatment with local excision is usually successful; ${ }^{9}$ however, in 1 case, wide excision with suprapubic cystotomy was required. ${ }^{3}$ Recurrence has been reported at varying intervals and is amendable to repeat excision. ${ }^{1,9}$ 


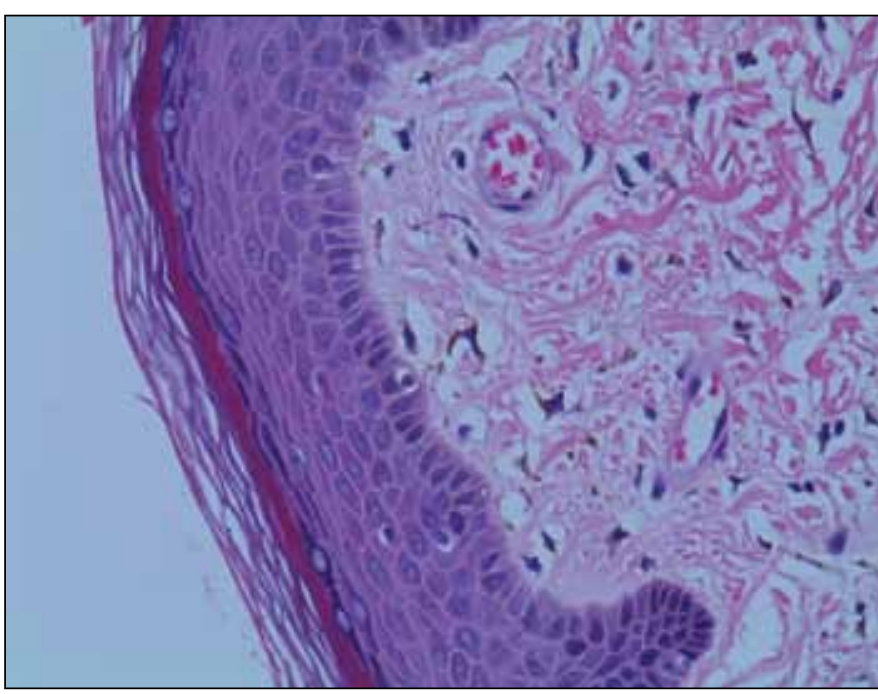

Fig. 2. Microscopic photograph (10x) hematoxylin and eosin stain showing normal appearing epidermis and stellate fibroblasts in the superficial dermis with hemosiderin pigment.

In 2012, Kampantais and colleagues summarized the literature and detailed 20 patients with penile FEPs; nine of these patients had a history of chronic condom catheter use, ${ }^{9}$ a finding echoed by Mason and colleagues in an earlier publication. ${ }^{15}$ Tsai and colleagues reported a penile FEP in a 50-year-old a man practicing genital-hanging Kung $\mathrm{Fu}$, which involves hanging heavy weights on the penis with the intention of achieving health benefits. ${ }^{20}$ Pediatric cases are often associated with prior penile surgery. ${ }^{21}$ There are other cases reported similar to our own, where no specific etiology can be identified. ${ }^{2,16}$

\section{Conclusion}

We report a fibroepithelial polyp of the glans penis. Unlike most reported cases, our case was not associated with chronic condom catheter use. As more cases of fibroepithelial polyps are documented, we suspect that the etiology will become more apparent. We speculate that some patients may withhold details of the true etiology of their penile lesions.

Competing interests: None declared.

This paper has been peer-reviewed.

\section{References}

1. Fetsch JF, Davis $\mathrm{CJ}$, Hallman JR, et al. Lymphedematous fibroepithelial polyps of the glans penis and prepuce: a clinicopathologic study of 7 cases demonstrating a strong association with chronic condom catheter use. Hum Pathol 2004;35:190-5. http://dx.doi.org/10.1016/i.humpath.2003.08.021

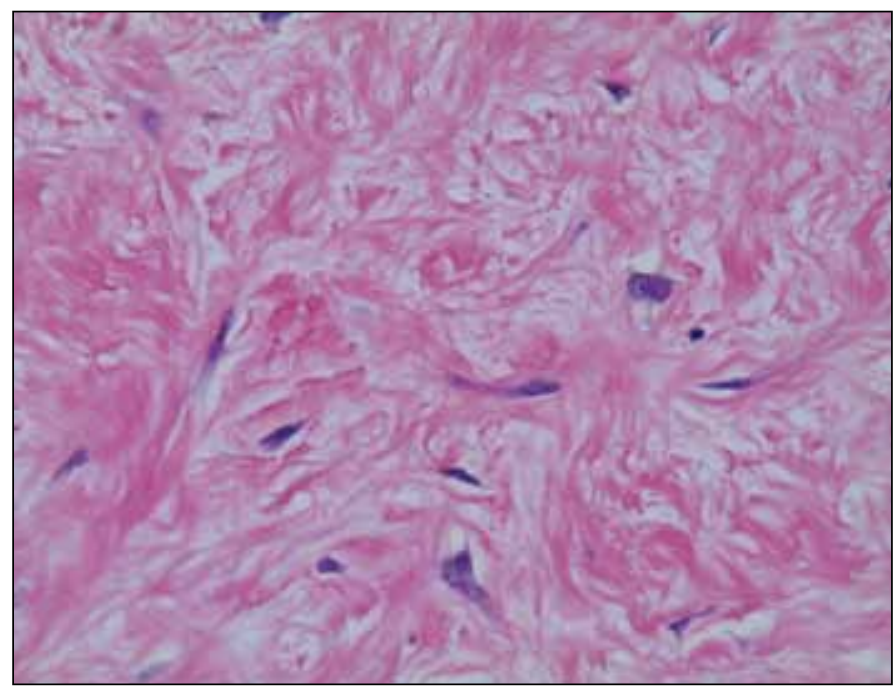

Fig. 3. Microscopic photograph (20x) Hematoxylin and eosin stain showing dermal edema and stellate fibroblasts.

2. Rodríguez Collar TL, Valdés Estévez B, López Marín L, et al. Penile fibroepithelial polyp. Case report. Arch Esp Urol 2010;63:309-12.

3. Kim YD, Lee MH, Kim JM, et al. Giant Fibroepithelial Polyp of the Glans Penis. Korean J Urol 2009;50:619. http://dx.doi.org/10.4111/kju.2009.50.6.619

4. Maskey AP, Almeida F, Farver C. Endobronchial fibroepithelial polyp. J Bronchology Interv Pulmonol 2012;19:313-4. http://dx.doi.org/10.1097/LBR.0b013e31826c5f42

5. Mangar W, Jiang D, Lloyd RV. Acute presentation of a fibroepithelial pharyngeal polyp. J Laryngol Otol 2004;118:727-9. http://dx.doi.org/10.1258/0022215042244697

6. Sari R, Akman A, Alpsoy E, et al. The metabolic profile in patients with skin tags. Clin Exp Med 2010;10:193-7. hitp://dx.doi.org/10.1007/s10238-009-0086-5

7. Brendler SJ, Watson RD, Katon RM, et al. Skin tags are not a risk factor for colorectal polyps. J Clin Gastroenterol 1989;11:299-302. hittp://dx.doi.org/10.1097/00004836-198906000-00011

8. Tsuzuki T, Epstein JI. Fibroepithelial polyp of the lower urinary tract in adults. Am I Surg Pathol 2005;29:460-6. http://dx.doi.org/10.1097/01.pas.0000155153.64360.1a

9. Kampantais $S$, Gourvas V, Lymperi S, et al. Malignant Degeneration Within a Fibroepithelial Polyp of the Glans Penis: a Case Report and Literature Review. Clin Genitourin Cancer 2013;11:63-5. http://dx.doi. org/10.1016/i.lgc.2012.07.001. Epub 2012 Sep 13.

10. Bromley B, Roberts DJ, Tracy EE, et al. Fibroepithelial bladder polyp and renal tubular dysgenesis: an unusual cause of third-trimester oligohydramnios. J Ultrasound Med 2001;20:1015-9.

11. Carrión López P, Domínguez Hinarejos C, Serrano Durbá A, et al. Congenital fibroepithelial polyps of the urethra [in Spanish]. Cir Pediatr 2010;23:7-9.

12. Huppmann AR, Pawel BR. Polyps and masses of the pediatric urinary bladder: a 21 -year pathology review. Pediatr Dev Pathol 2011;14:438-44. http://dx.doi.org/10.2350/11-01-0958-0A.1

13. Kojima Y, Lambert SM, Steixner BL, et al. Multiple metachronous fibroepithelial polyps in children. J Urol 2011;185:1053-7. http://dx.doi.org/10.1016/i.juro.2010.10.046

14. Banerij IS, Shah S, Kekre NS. Fibroepithelial polyp of the prepuce: A rare complication of long-term condom catheter usage. Indian J Urol 2008;24:263-4. http://dx.doi.org/10.4103/0970-1591.40628

15. Mason SE, DeVilliers $P$, Andea AA. Lymphedematous fibroepithelial polyps of the penis associated with long-term condom catheter use: case report and review of the literature. J Cutan Pathol 2009;36:906-9. http://dx.doi.org/10.1111/i.1600-0560.2008.01133.x

16. Pe-a KBG, Parada DD. Lymphedematous fibroepithelial polyp of the glans penis non-associated with condom catheter use. APMIS 2008;116:215-8. http://dx.doi.org/10.1111/j.1600-0463.2008.00920.x

17. Safi F, Bekdache 0 , Al-Salam S, et al. Management of peri-anal giant condyloma acuminatum-A case report and literature review. Asian J Surg 2013;36:43-52. http://dx.doi.org/10.1016/i.asjsur.2012.06.013

18. Agir H, Sen C, Cek D. Squamous cell carcinoma arising from a fibroepithelial polyp. Ann Plast Surg 2005;55:687-8. http://dx.doi.org/10.1097/01.sap.0000181644.93420.4f

19. Zervas $A$, Rassidakis $G$, Nakopoulou $L$, et al. Transitional cell carcinoma arising from a fibroepithelial ureteral polyp in a patient with duplicated upper urinary tract. J Urol 1997;157:2252-3. http://dx.doi. org/10.1016/S0022-5347(01)64738-4

20. Tsai T-F, Hung C-S, Hsiao C-H. Fibroepithelial polyp of glans penis in a man who practiced genital hanging kung fu. J Am Acad Dermatol 2008;59:S35-7. http://dx.doi.org/10.1016/i.jaad.2007.07.048 
Yan et al.

21. Yildirim I, Irkilata C, Sumer F, et al. Fibroepithelial polyp originating from the glans penis in a child. Int J Urol 2004;11:187-8. http://dx.doi.org/10.1111/i.1442-2042.2003.00757.x
Correspondence: Dr. Hanmu Yan, Division of Urology, University of Toronto, Toronto, ON; hanmu.yan@gmail.com 